\title{
BIOCONTROL OF PESTS IN APPLES UNDER INTEGRATED FRUIT PRODUCTION
}

\author{
P.W. SHAW and D.R. WALLIS \\ The Horticulture and Food Research Institute of New Zealand Limited \\ (HortResearch), Old Mill Road, RD3 Motueka 7198, New Zealand \\ Corresponding author:pshaw@hortresearch.co.nz
}

\begin{abstract}
The biological control of some key orchard pests achieved within an Integrated Fruit Production (IFP) apple block was assessed. Insecticide sprays were used to manipulate the numbers of natural enemies. Treatments included applications of the broad-spectrum insecticide carbaryl, a selective insecticide programme (IFP) and a control (no insecticides). Plots treated with carbaryl became heavily infested with woolly apple aphid and European red mite. However, carbaryl sprays did not completely prevent lacewings, ladybirds and the woolly apple aphid parasitoid Aphelinus mali subsequently moving into the plots in response to the high host populations. Numbers of some natural enemies were reduced in the carbaryl treatment and the trees were damaged by mites and woolly apple aphids. The selective and no-insecticide programmes did not disrupt natural enemies and pest levels in trees and fruit were similar and acceptable.
\end{abstract}

Keywords: biological control, natural enemies, insecticide sprays, apple, integrated fruit production.

\section{INTRODUCTION}

The Integrated Fruit Production (IFP) programme for New Zealand pipfruit was developed to address increasing consumer concern over pesticide residues in food, and the need for more sustainable, environmentally sensitive production practices (Batchelor et al. 1997). Pest management within the IFP programme places greater emphasis on biological control, complemented by a reduction in pesticide use and the adoption of more selective and environmentally benign products (Walker et al. 1991; Wearing 1997).

In New Zealand, in the absence of disruptive insecticides, natural enemies can control key orchard pests such as European red mite (Panonychus ulmi, ERM) (Collyer 1976), woolly apple aphid (Eriosoma lanigerum, WAA) (Shaw et al. 1997; Shaw \& Walker 1996), apple leafcurling midge (Dasineura mali, ALCM) (Shaw et al. 2003) and leafrollers (Suckling et al. 1998).

The aim of the current study was to demonstrate the ability of natural enemies to control arthropod pests in an IFP insecticide programme, and to compare these results with those where a broad-spectrum insecticide, carbaryl, was used in an attempt to disrupt natural enemies.

\section{METHODS}

The trial was carried out in a fifteen-year-old block of 'Braeburn' apples at the HortResearch orchard in Nelson. The trees were approximately $3 \mathrm{~m}$ high with a tree/ row spacing of $2.7 \times 4.7 \mathrm{~m}$. The block had received an IFP pesticide programme for 7 years, and past monitoring indicated that it had had relatively predictable populations of arthropod pests and natural enemies for the last four seasons.

Most trees received one of two insecticide treatments: either five applications of IFP insecticides methoxyfenozide (Prodigy ${ }^{\mathrm{TM}}$; $180 \mathrm{~g}$ ai/ha; 16 November 2007), indoxacarb (Avaunt ${ }^{\circledR} 30 W G ; 120 \mathrm{~g}$ ai/ha; 5 December 2007) and ememectin benzoate (Proclaim $\AA$; $2 \mathrm{~g}$ ai/ha; 8 January 2008, 8 February 2008 and 6 March 2008) or eleven applications 
of carbaryl (Sevin® Flo; $2 \mathrm{~kg}$ ai/ha) between 31 October 2007 and 3 April 2008. Some trees (controls) were not treated with insecticide. The whole trial block received an application of $2 \%$ mineral oil and buprofezin (Ovation ${ }^{\mathrm{TM}} 50 \mathrm{WDG} ; 250 \mathrm{~g}$ ai/ha) on 21 August 2007 and fungicides were applied through the season. All sprays were applied using an airblast sprayer and a water rate of 2000 litres/ha.

Each treatment was replicated twice, with each plot consisting of 54 trees ( $0.068 \mathrm{ha})$. The two carbaryl-treated plots were set up adjacent to each other in the centre of the block to provide a larger area $(0.136 \mathrm{ha})$, in order to minimise the effect of immigration of natural enemies originating from the other treatments.

Fifteen beating tray $(500 \times 500 \mathrm{~mm})$ samples per plot were taken by striking a lower branch of individual trees three times with a padded piece of metal pipe. Sampling was carried out on 29 November 2007, 18 January 2008 and 20 March 2008 and the arthropod natural enemies captured were identified and counted. Between 3 September 2007 and 21 April 2008, one yellow sticky trap $(180 \times 190 \mathrm{~mm})$ was hung vertically inside a tree in each plot to catch insects. The traps were checked and replaced weekly, using a binocular microscope to help identify and count trapped insects. One hundred growing shoots per plot were examined for the presence of WAA and ALCM on 7 December 2007, 11 January 2008 and 19 March 2008. On 29 February 2008, a random 25-leaf sample was collected to monitor mites from each treatment (13 leaves and 12 leaves respectively from each plot). Leaves were brushed with the aid of a mite brushing machine (Leedom Engineering, California) and the numbers of active ERM and Typhlodromus pyri predatory mites were counted. Between 4 March and 21 April 2008, six test tubes containing general purpose artificial diet (Singh 1983), each placed inside a length of black irrigation tubing, were taped to branches (one tube per tree) to monitor earwigs in each plot. A random sample of 800 fruit was harvested from each plot on $28 \mathrm{March}$ 2008 and the numbers of fruit infested or damaged by insects was recorded.

\section{RESULTS AND DISCUSSION}

WAA, ERM and ALCM were the main arthropod pests recorded. Key natural enemies recorded from beating tray samples and yellow sticky traps were Aphelinus mali (WAA egg parasitoid), Sejanus albisignata (a mirid bug predator of mites and ALCM eggs), lacewings (aphid predators), Platygaster demades (ALCM egg parasitoid) and Anystis sp. (a predatory mite). Other incidental natural enemies recorded in all treatments included Anagrus sp. (an egg parasitoid of Froggatt's apple leafhopper), Trichogramma spp. (egg parasitoids of leafroller and noctuid moths), Stethorus bifidus (a ladybird predator of ERM and other tetranychid mites), spiders and Encarsia spp. (parasitoids of armoured scale insects and other Coccoidea).

Numbers of key natural enemies were similar and low when the first beating tray sample was taken on 29 November 2007 (Fig. 1). During January, pest levels increased and monitoring results from both beating trays and sticky traps indicated that A. mali was suppressed in the carbaryl treatment, allowing much higher levels of WAA shoot infestation to develop than in the IFP and control treatments (Figs $1 \& 2$ ). Carbaryl is known to be toxic to beneficial insects including A. mali (Bradley et al. 1997). However carbaryl, which is a quick 'knockdown' insecticide with low persistence, did not prevent higher numbers of A. mali and lacewings moving into the carbaryl-treated plots during the season in response to the increasing WAA population (Fig. 2). WAA was not affected by the insecticide. Earwigs, which are WAA predators, were recovered from three diet tubes in the IFP and five diet tubes in the control treatments. No earwigs were recorded in the carbaryl treatment. In the final beating tray sample in March, predatory assassin bugs (Reduviidae) and damsel bugs (Nabidae), which can feed on small insects including aphids, were more common in the IFP and control treatments (data not shown). The generalist predatory mite, Anystis sp., was more common in beating tray samples in the unsprayed control treatment that in either sprayed treatment (Fig. 1). 

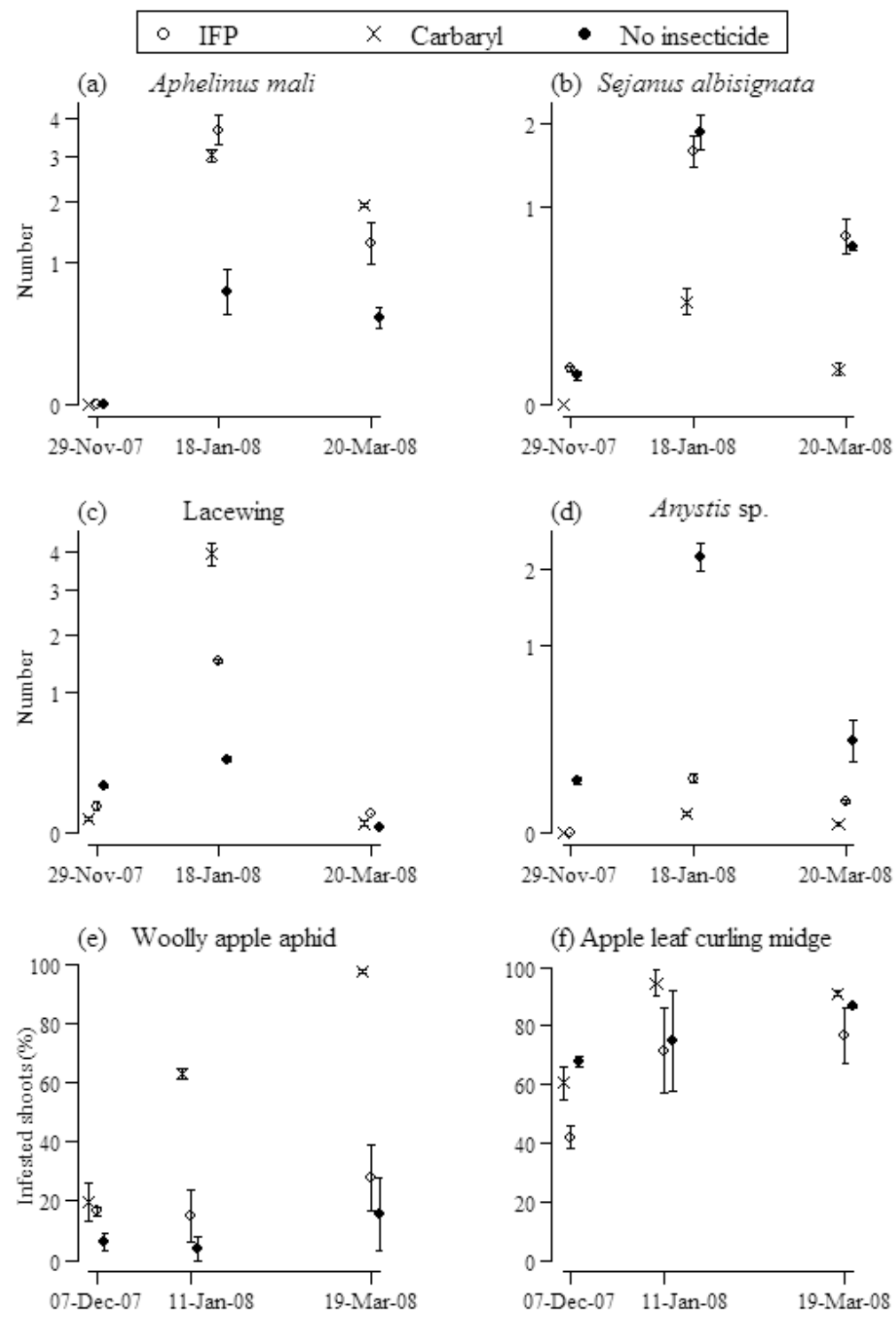

(f) Apple leaf curling midge

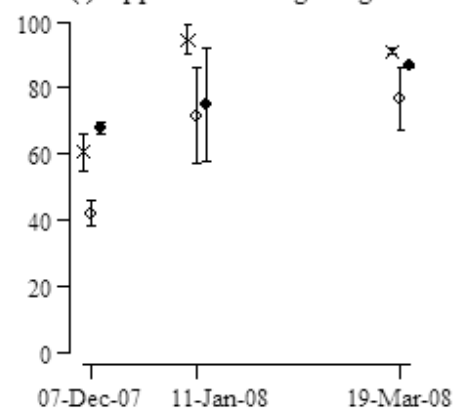

FIGURE 1: Mean number per beating tray sample (values plotted on square root scale) of four natural enemies, (a) Aphelinus mali; (b) Sejanus albisignata; (c) Lacewing and (d) Anystis sp., and the mean percentage of apple shoots infested with (e) woolly apple aphid and (f) apple leafcurling midge. Values presented are means for the Integrated Fruit Production (IFP), carbaryl and no insecticide treatments on three dates. Error bars indicate standard errors of means. 
The late influx of WAA natural enemies into the carbaryl treatment had little impact on the WAA population at harvest and $64 \%$ of fruit in the harvest sample were infested with WAA, compared with $4 \%$ and $1 \%$ respectively in the IFP and control treatments. WAA pressure from the heavily infested carbaryl treatment probably increased infestation levels in the IFP and control treatments. Leafroller and other pest damage on fruit was low $(<1 \%)$ in all treatments.

The beating tray results indicated that the higher numbers of Sejanus albisignata in the IFP and control treatments in January probably contributed to a ca $25 \%$ reduction in ALCM shoot infestation in these treatments compared with the carbaryl treatment at this time (Fig. 1). However, sticky trap catches showed that continued carbaryl applications did not prevent movement of the predatory bug or the ALCM egg parasitoid Platygaster demades into carbaryl-treated plots later in the season (Fig. 2).
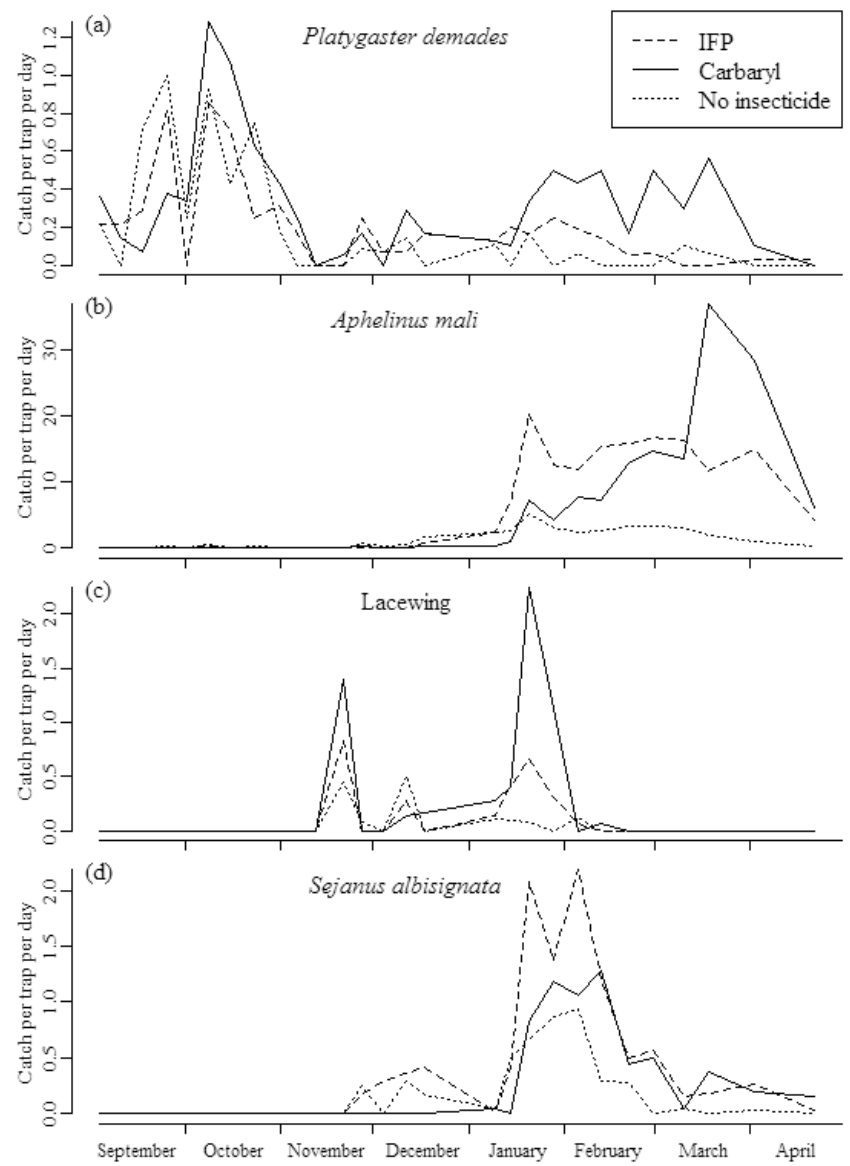

FIGURE 2: The number of natural enemies, (a) Platygaster demades; (b) Aphelinus mali; (c) Lacewing and (d) Sejanus albisignata, per trap per day caught in sticky traps between September 2007 and April 2008. Values presented are means for the Integrated Fruit Production (IFP), carbaryl and no insecticide treatments. 
Damaging levels of ERM (120 per leaf) were recorded in February in the carbaryl treatment compared with 1.2 and 0.8 per leaf in the IFP insecticide and control treatments respectively. The carbaryl treatment had an unfavourable pest to predator mite (Typhlodromus pyri) ratio of 136:1 compared with ca 3:1 in the IFP and control treatments. The high mite population in the carbaryl treatment attracted small numbers of the ERM ladybird predator Stethorus bifidus, which was not totally excluded by the disruptive insecticide (data not shown).

The relatively small size of the trial plots, the mobility of some of the natural enemies monitored and the inability of carbaryl to exclude them totally from treated plots makes interpretation of the results difficult. The IFP insecticides used in this trial are effective against leafrollers and codling moth, but not against WAA, ERM or ALCM, which were the key pests monitored. Results indicate that the natural enemies in the IFP programme were not noticeably disrupted and were able to provide effective control of key orchard pests.

Although IFP growers may apply a single application of carbaryl for fruit thinning or of diazinon for WAA control to some apple blocks within their orchards, such use of a broad spectrum but low persistence insecticide is likely to cause only a temporary disruption to biocontrol, as many natural enemies are sufficiently mobile to recolonise treated blocks from surrounding untreated areas within the orchard. Biological control of insect pests is an important aspect of IFP, which thus provides a more sustainable production system for orchardists.

\section{ACKNOWLEDGEMENTS}

We thank Nelson research orchard staff for applying the spray treatments. This project was funded by the New Zealand Foundation for Research, Science and Technology.

\section{REFERENCES}

Batchelor TA, Walker JTS, Manktelow DWL 1997. New Zealand integrated fruit production for pipfruit - charting a new course. Proceedings of the 50th New Zealand Plant Protection Society Conference. Pp. 14-19.

Bradley SJ, Murrell VC, Shaw PW, Walker JTS 1997. Effect of orchard pesticides on Aphelinus mali, the woolly apple aphid parasitoid. Proceedings of the 50th New Zealand Plant Protection Society Conference. Pp. 218-222.

Collyer E 1976. Integrated control of apple pests in New Zealand 6. Incidence of European red mite, Panonychus ulmi (Koch), and its predators. New Zealand Journal of Zoology 3: 39-50.

Shaw PW, Bradley SJ, Walker JTS 1997. The impact of early season insecticides in an integrated fruit production programme on apple. Proceedings of the 50th New Zealand Plant Protection Society Conference. Pp. 283-287.

Shaw PW, Walker JTS 1996. Biological control of woolly apple aphid by Aphelinus mali in an integrated fruit production programme in Nelson. Proceedings of the 49th New Zealand Plant Protection Society Conference. Pp. 59-63.

Shaw PW, Wallis DR, Rogers DJ 2003. The impact of early season insecticides on biological control of apple leafcurling midge (Dasineura mali). New Zealand Plant Protection 56: 164-167.

Suckling DM, Burnip GM, Walker JTS, Shaw PW, McLaren GF, Howard CR, Lo P, White V, Fraser J 1998. Abundance of leafrollers and their parasitoids on selected host plants in New Zealand. New Zealand Journal of Crop and Horticultural Science 26: 193-203.

Walker JTS, Baynon GT, White V 1991. Insect control on apples with RH- 5992, a novel insect growth regulator. Proceedings of the 44th New Zealand Plant Protection Society Conference. Pp. 66-69.

Wearing CH 1997. Indicators of sustainable pest management in orchard production systems. Proceedings of the 50th New Zealand Plant Protection Society Conference. Pp. 283-287. 